\title{
DNA damaging agent-induced autophagy produces a cytoprotective adenosine triphosphate surge in malignant glioma cells
}

\author{
M Katayama ${ }^{1}$, T Kawaguchi ${ }^{1}$, MS Berger ${ }^{1}$ and RO Pieper ${ }^{\star, 1}$
}

\begin{abstract}
Although autophagy enhances cell survival in nutrient-deprived cells by increasing adenosine triphosphate (ATP) production, it remains unclear if autophagy functions similarly in cells treated with cytotoxic chemotherapy agents. To address this issue, we measured both the ability of DNA damaging agents (Temozolomide, and Etoposide) to induce an autophagy-dependent production of ATP, and the effects of modulation of autophagy on drug-induced cell death. Both drugs induced an autophagyassociated increase in ATP production in multiple glioma cell lines. The drug-induced ATP surge could not be blocked by glucose starvation, but could be blocked by preincubation with the autophagy inhibitor 3-methyladenine (3-MA), an siRNA targeting beclin 1, or the mitochondrial inhibitor oligomycin. Inhibition of autophagy-induced ATP production increased nonapoptotic cell death associated with micronucleation, while restoration of the 3-MA-inhibited ATP surge by addition of pyruvate suppressed cell death. These results show that DNA damaging agents induce an autophagy-associated ATP surge that protects cells and may contribute to drug resistance.
\end{abstract}

Cell Death and Differentiation (2007) 14, 548-558. doi:10.1038/sj.cdd.4402030; published online 1 September 2006

Autophagy is a process by which subcellular constituents are degraded in autophagosomes/autolysosomes in response to stress. ${ }^{1}$ Whereas growth factors enhance the ability of metazoan cells to take up extracelluar nutrients and suppress autophagy, deprivation of either growth factors or extracellular nutrients leads to decreased nutrient uptake and derepression of autophagy. The catabolic autophagy process is believed to allow starving cells to support adenosine triphosphate (ATP) production and avoid cell death. ${ }^{2,3}$

The autophagic process is regulated by both class I and class III phosphatidylinositol 3-kinase (PI3K) pathways. ${ }^{2,4,5}$ Mammalian target of Rapamycin (mTOR) functions downstream of the class-I PI3K/Akt, and is a key negative regulator of autophagy. In this role, mTOR serves as a metabolic sensor that coordinates crosstalk between nutrient availability and autophagy. ${ }^{6,7}$ In contrast, class III PI3K positively regulates autophagy. The formation of a preautophagosomal isolation membrane that encloses cytoplasmic cargo is positively regulated by phosphatidylinositol 3-phosphate, the products of class III PI3K phosphorylation. ${ }^{4}$ It has also been suggested that the trafficking of autophagosomes is regulated by class III PI3Ks, ${ }^{4,5}$ an idea supported by the observation that 3methyladenine (3-MA), which inhibits class III PI3K activity, also inhibits autophagosome formation and is widely used as an autophagy inhibitor. ${ }^{5}$

It is also known that autophagy is induced in cancer cells derived from tissues such as breast, colon, prostate and brain in response to a variety of anticancer therapies. ${ }^{3,8}$ However, autophagy in response to these drugs can produce different outcomes, in some cases promoting cell adaptation and survival similar to what is seen in nutrient deprived cells, while in other cases, inducing programmed cell death type. The role of drug-induced autophagy in cell death or survival is therefore unresolved..$^{3,8}$

Temozolomide (TMZ) is an alkylating agent which is widely used for treating primary and recurrent high-grade gliomas. ${ }^{9}$ The cytotoxicity of $\mathrm{TMZ}$ is thought to result from the formation of $0^{6}$-methylguanine in DNA, which mispairs with thymine during DNA replication triggering futile cycles of the mismatch repair system and subsequent DNA damage. ${ }^{10}$ In glioma cells, the DNA damage induces a G2/M arrest, not apoptosis, and cell death occurs mainly by cell death associated with multimicronucleation, particularly in p53-deficient cells. ${ }^{11,12}$ In a previous study, it was shown that $\mathrm{TMZ}$ induces autophagy, and that pharmacological inhibition of autophagy could influence cellular oucome. ${ }^{13}$ The exact means by which this occurred, however, and the potential role of autophagy -induced ATP production in the process, were not determined. In the present study, we investigated the relationship between autophagy, autophagy-associated ATP production, and cell death in response to $\mathrm{TMZ}$ and a second DNA damaging agent Etoposide.

\section{Results}

Effect of TMZ on malignant glioma cell lines. To begin to examine the antitumor effect of $T M Z$ on malignant glioma cell lines, unsychronized U251 GBM cells were first treated with

\footnotetext{
${ }^{1}$ Department of Neurological Surgery and the Brain Tumor Research Center, University of California, San Francisco, CA, USA

${ }^{*}$ Corresponding author: RO Pieper, Neurological Surgery and The Brain Tumor Research Center, University of California, San Franscisco, 2340 Sutter St, Rm N261, San Francisco, CA 94115-0875, USA. Tel: 415-502-7132; Fax: + 415-502-6779; E-mail: rpieper@cc.ucsf.edu

Keywords: autophagy; Temozolomide; Etoposide; glioma; ATP

Abbreviations: TMZ, Temozolomide; 3-MA, 3-methyladenine; ATP, adenosine triphosphate; PI3K, phosphatidylinositol 3-kinase; MAP1-LC3, microtubule-associated protein 1 light-chain 3

Received 08.3.06; revised 12.7.06; accepted 19.7.06; Edited by E Baeherecke; published online 01.9.06
} 
TMZ (100 $\mu \mathrm{M}$ for $3 \mathrm{~h})$ and further incubated for 3-14 days in the absence of $T M Z$, after which cells were analyzed by FACS for DNA content. Consistent with previous reports, ${ }^{11-13}$ cells accumulated with $4 \mathrm{~N}$ DNA content at the G2-M boundary, with ratio of $4 \mathrm{~N} / 2 \mathrm{~N}$ DNA content peaking 3 days after TMZ treatment and decreasing gradually to base levels by 10 days post-TMZ exposure (Figures $1 \mathrm{a}$ and $\mathrm{b}$ ).

TMZ was previously shown in p53-deficient glioma cells to induce cell death characterized by multimicronucleation in the absence of cytoplasmic shrinkage ('mitotic catastrophe'). ${ }^{11,12}$ Consistent with this observation, TMZ treated p53-deficient U251 cells stained with hematoxylin/ eosin exhibited multiple, micronucleated nuclei in the absence of cytoplasm shrinkage (arrows, Figure 1c), with this form of cell death peaking 5-7 days post-TMZ exposure (2-4 days after the maximal G2 arrest; Figure 1b). Consistent with previous reports, no apoptotic cells were detected microscopically or by cell cycle analysis (lack of cells with sub-G1 DNA content). ${ }^{11-13}$

Finally, because recent investigations also demonstrated that radiation or chemotherapeutic agents including $\mathrm{TMZ}$ induce autophagy in malignant glioma cells, ${ }^{13,14}$ we measured conversion of microtubule-associated protein 1 lightchain 3 (MAP1-LC3) (LC3-I, $18 \mathrm{kDa}$ ), to a lipidized form (LC3II, $16 \mathrm{kDa}$ ) in TMZ-treated cells as a measure of autophagy. As shown in Figure 1d, TMZ induced an accumulation of the
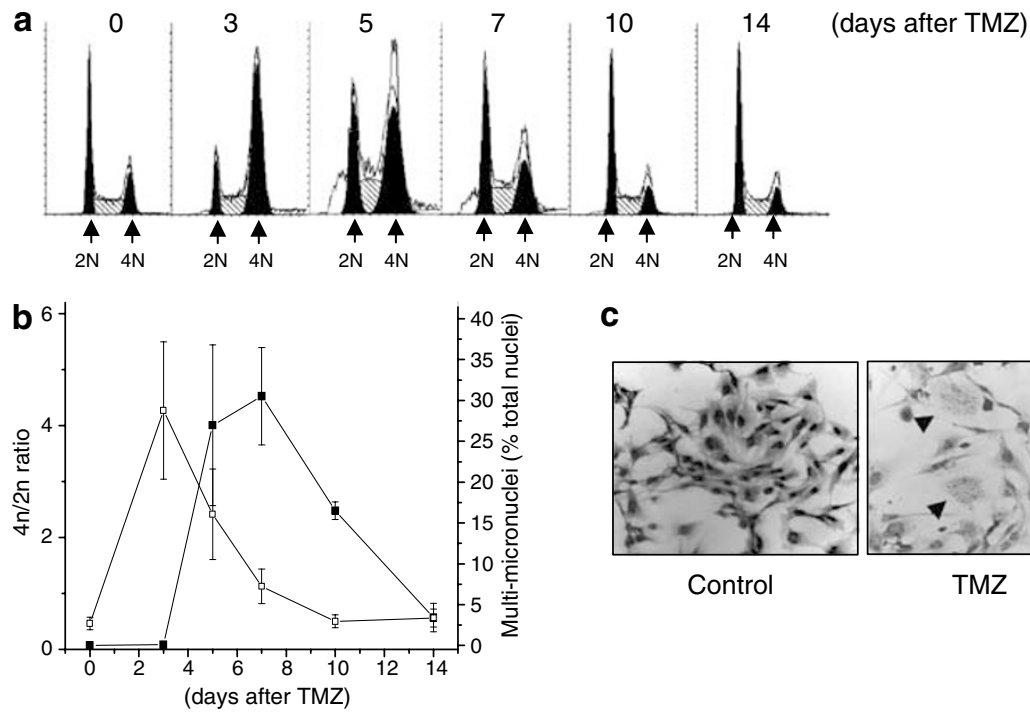

C

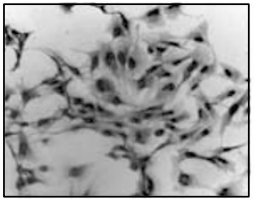

Control

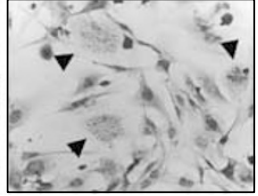

TMZ

d

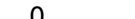

5

$0 \quad$ (days after TMZ)
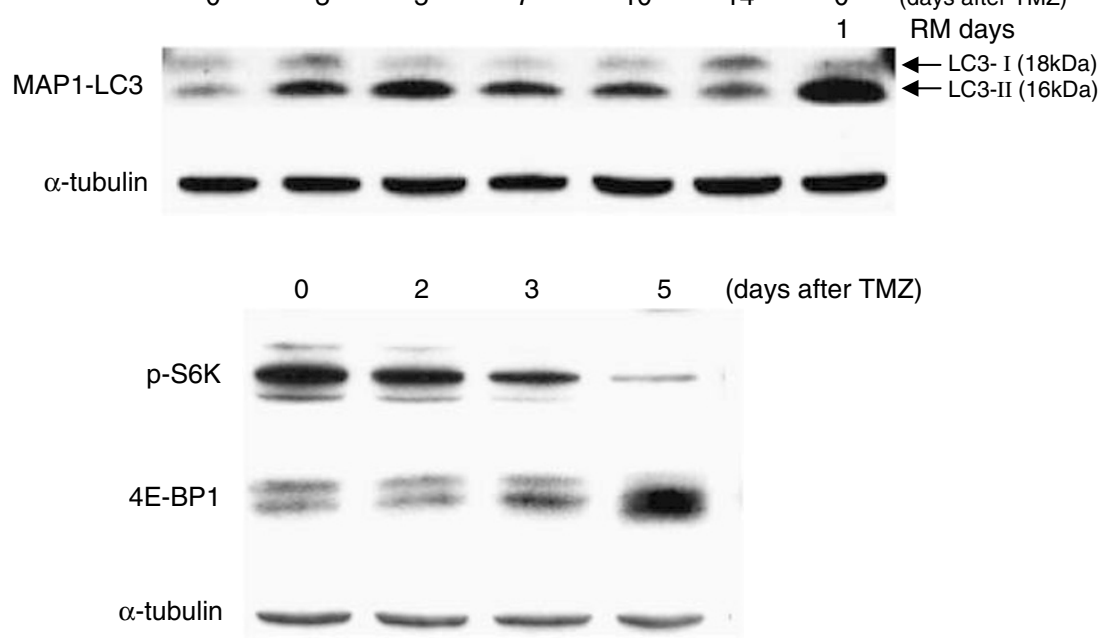

Figure 1 Effect of TMZ on U251 cells. U251 cells were exposed to TMZ (100 $\mu \mathrm{M}, 3 \mathrm{~h}$ ), after which cells were washed, placed in drug-free media, and monitored for DNA content by FACS analysis. Representative histograms derived from cells 3-14 days after TMZ exposure are shown in (a), and the 4N/2N ratios (means \pm S.D.) are shown as open squares in (b). (c) Representative photomicrographs $(\times 400)$ of hematoxylin/eosin-stained cells 7 days after TMZ-exposure $(0$ or $100 \mu \mathrm{M}, 3 \mathrm{~h})$. Arrowheads identify cells exhibiting multimicronucleation in the absence of cytoplasmic shrinkage. The mean percentages \pm S.D. of TMZ-treated U251 cells that underwent cell death characterized by multimicronucleation in the absence of cytoplasmic shrinkage following 3-14 days after TMZ exposure are shown as closed squares in (b). (d) Immunoblot analysis of MAP1LC3 forms in control U251 cells and in U251 cells 3-14 days after TMZ exposure (100 uM, 3h), or 1 day after rapamycin (RM, $10 \mathrm{nM}$ ) exposure (positive control) showing the conversion of the LC3-I form of MAP1-LC3 to the LC3-II form beginning 3 days after TMZ exposure. (e) Immunoblot analyses of levels of phospho-S6K, 4E-BP1 in TMZtreated $(100 \mu \mathrm{M}, 3 \mathrm{~h}) \mathrm{U} 251$ cells $0-5$ days following drug exposure (e). $\alpha$-Tubulin was used as a loading control in panels $d$ and e. All data are representative of three independent experiments 
LC3-II form of MAP1-LC3 as early as 3 days after TMZ exposure, similar to what was noted following a 1-day exposure of the cells to the known inducer of autophagy, rapamycin. To further verify that TMZ-induced autophagy was occurring, we indirectly measured the activity of mTOR, a key suppressor of autophagy, by looking at activation of its downstream targets S6K and 4E-BP1 in TMZ-treated cells. As shown in Figure 1e, the phosphorylation of S6K was significantly downregulated 3 days following TMZ exposure, and 4E-BP1 was progressively hypophosphorylated (faster migrating band), consistent with downregulation of mTOR activity that accompanies autophagy. These results indicate that $\mathrm{TMZ}$ induces a G2 arrest followed by the induction of autophagy and a form of cell death preceded by multimicronucleation ('mitotic catastrophe').
TMZ-induced, autophagy-driven increases in ATP levels protect cells from the drug-induced cell death preceded by multinucleation. Because it has been reported that autophagy provides mitochondria with substrates to maintain oxidative phosphorylation in the absence of growth factors, ${ }^{15}$ we examined whether TMZ-induced autophagy could have a similar ATP-producing effect. To assess the effects of TMZ on the levels of ATP, we used a luciferin-luciferase based ATP bioluminescence method that has been described previously. ${ }^{16}$ ATP levels in U251 cells increased 3 days following TMZ exposure and peaked at over two times those of control cells 7 days after TMZ exposure, falling to control levels by 14 days after $T M Z$ treatment (Figure 2a). The time course of the ATP surge was consistent with that of autophagic processing of MAP1-LC3 to its lipidized form
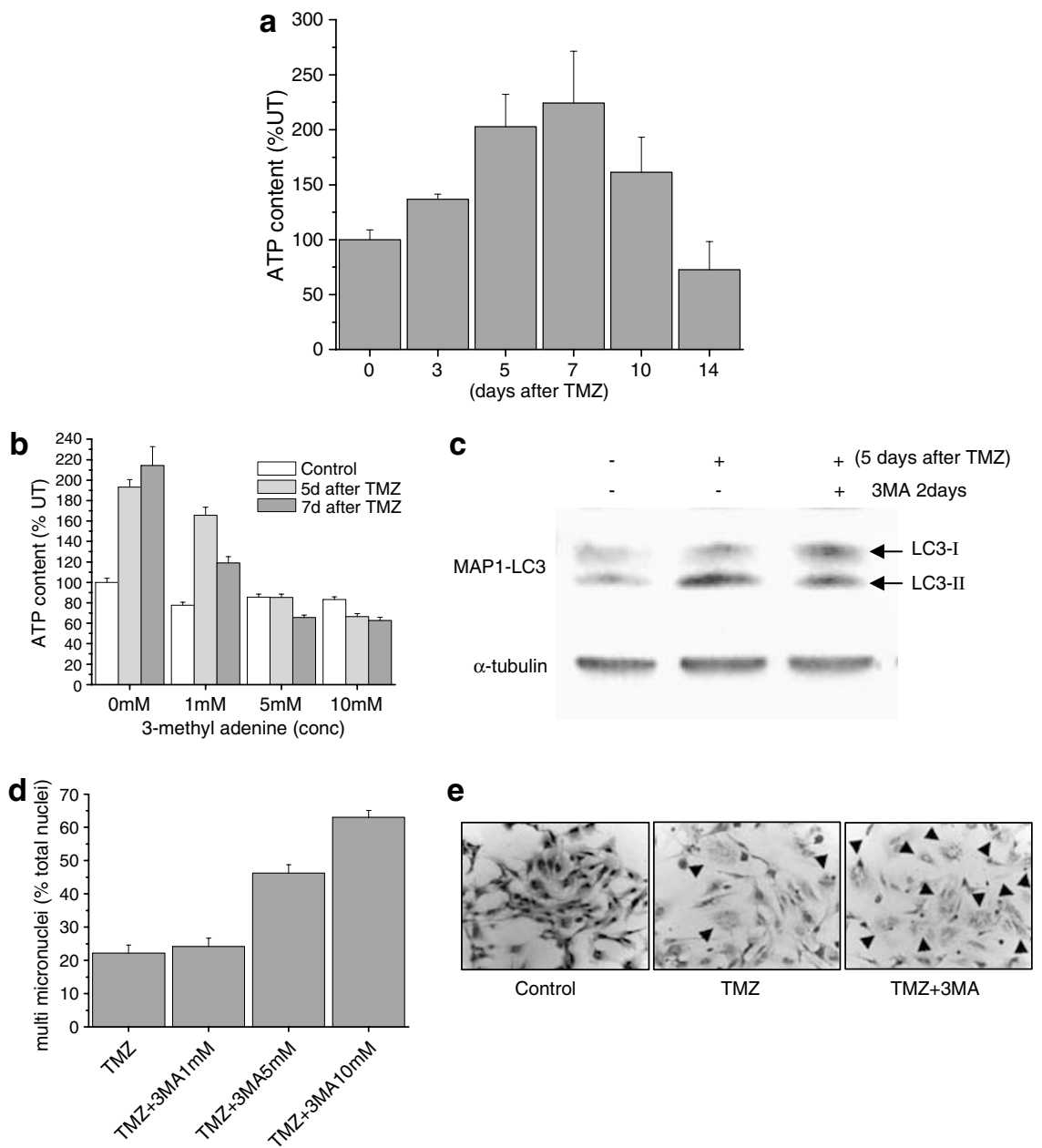

Figure 2 TMZ-induced, autophagy-driven increases in ATP levels protect U251 cells from cell death preceded by multinucleation. (a) ATP levels (mean \pm S.D., normalized to untreated controls) per cell 3-14 days after TMZ treatment (100 $\mu \mathrm{M}, 3 \mathrm{~h}$ ). (b) ATP levels (mean \pm S.D., normalized to untreated controls) in cells $5-7$ days after TMZ $(100 \mu \mathrm{M}, 3 \mathrm{~h})$ exposure with the addition of 3-MA $(0-10 \mathrm{mM})$ for the last 2 days of the experiment. (c) Immunoblot analyses of the levels of LC3-I and LC3-II forms of MAP1-LC3 in control cells (lane 1), cells 5 days after TMZ treatment (100 $\mu \mathrm{M}, 3 \mathrm{~h}$ ) (lane 2), or cells collected 5 days after TMZ treatment (100 $\mu \mathrm{M}, 3 \mathrm{~h}$ ) with the addition of $3-\mathrm{MA}$ $(10 \mathrm{mM})$ the last 2 days of the study (lane 3 ). $\alpha$-Tubulin was used as a loading control. (d) Percentage of cells that underwent multimicronucleation 5 days after TMZ treatment $(100 \mu \mathrm{M}, 3 \mathrm{~h})$ with the addition of 3-MA $(0-10 \mathrm{mM})$ the last 2 days of the study. (e) Photomicrograph $(400 \times)$ of hematoxylin/eosin-stained cells 5 days after exposure to TMZ $(100 \mu \mathrm{M}, 3$ days) with the addition of $3-\mathrm{MA}(0-10 \mathrm{mM})$ the last 2 days of the study (arrows: multinucleated cells). All studies are representative of three independent experiments 
(LC3-II) (Figure 1d), suggesting that this surge could be an autophagy-related process.

To clarify whether the TMZ-induced elevation of ATP levels was related to autophagy, we exposed cells to TMZ ( 0 or $100 \mu \mathrm{M}, 3 \mathrm{~h}$ ), then incubated the cells with 3-MA (a PI3K inhibitor widely used as a pharmacological inhibitor of autophagy), for 2 days beginning 3 days after TMZ exposure, and monitored effects on ATP production and autophagy. While 3-MA alone had no effect on ATP levels, the TMZinduced ATP surge ( $0 \mathrm{mM}$ group; Figure $2 \mathrm{~b}$ ) was inhibited by the addition of 3-MA in a dose dependent manner. 3-MA similarly did not alter the distribution between MAP1-LC3 forms (not shown), but inhibited the TMZ-induced conversion of MAP1-LC3 to a lipidized form (Figure 2c). To determine if the autophagy-associated surge in ATP was related to cell outcome, we also monitored the percentage of cells under- going multimicronucleation in cells treated similarly with $T M Z$, 3-MA or both. While a 2-4 day treatment with 3-MA up to $10 \mathrm{mM}$ alone did not induce cell death (data not shown), the delayed 3-MA exposure that suppressed the TMZ-induced ATP surge also significantly increased the percentage of cells undergoing multimicronucleation in a dose-dependent manner (Figures 2d and e).

Because 3-MA is a relatively nonspecific inhibitor of autophagy, especially when used at high concentrations, we repeated the studies in Figure 2 using an short hair pin RNA (shRNA) targeting beclin-1, a key component of autophagosome formation. As shown in the Western blot in Figure 3a, U251 cells stably expressing beclin shRNA exhibited significantly lower levels of beclin 1 relative to cells expressing a nontargeted shRNA (shNegCtrl). Cells expressing beclin shRNA also exhibited reduced conversion of MAP1-LC3 to a

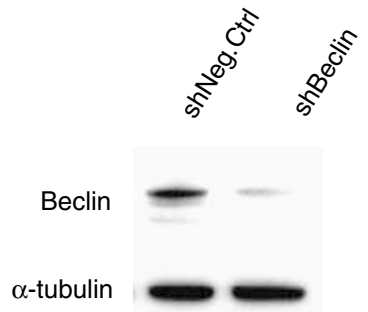

C

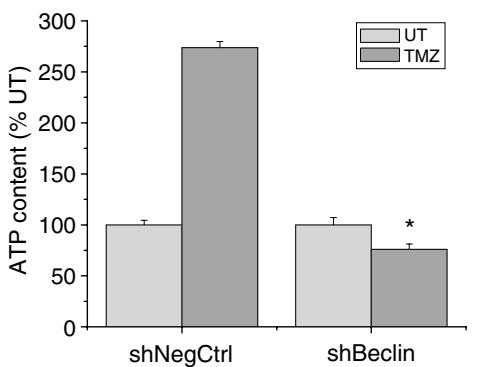

e



b

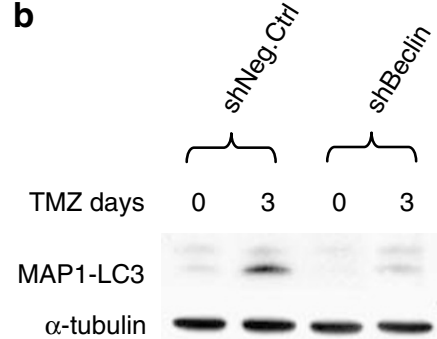

d
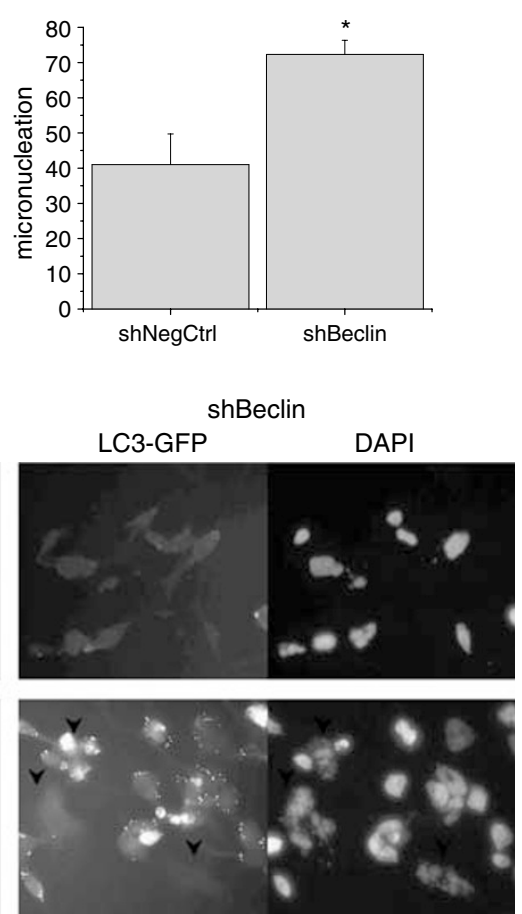

Figure 3 shRNA-mediated suppression of beclin expression suppresses TMZ-induced autophagy and ATP accumulation, and enhances multimicronucleation. (a) Western blot analysis of beclin1 levels in U251 cells stabley expressing negative control shRNA or shRNA targeting beclin 1. (b) Western blot analysis of MAP1-LC3 I and II 0 or 3 days following TMZ exposure $(100 \mu \mathrm{M}, 3 \mathrm{~h})$ of U251 cells stabley expressing negative control shRNA or shRNA targeting beclin 1. (c) ATP content 5 days after TMZ exposure $(0 \mu \mathrm{M}$, light gray bars; or $100 \mu \mathrm{M}$, dark gray bars, $3 \mathrm{~h})$ of U251 cells stabley expressing negative control shRNA or shRNA targeting beclin 1. (d) percentage of $\mathrm{U} 251$ cells stabley expressing negative control shRNA or shRNA targeting beclin 1 that exhibit micronucleation 5 days following TMZ (100 $\mu$ M, $3 \mathrm{~h}$ ) exposure. (e) Fluorescent images of unstained (left panels) or DAPI-stained (right panels) GFP-LC3-expressing U251cells also expressing either negative control shRNA (shNegCtr) or shRNA targeting beclin 1 (sh Beclin) 5 days following exposure to 0 (UT) or $100 \mu \mathrm{M} \mathrm{TMZ} \mathrm{(TMZ)(3h).} \mathrm{Arrowheads,} \mathrm{cells} \mathrm{exhibiting} \mathrm{condensed} \mathrm{GFP-LC3} \mathrm{speckles} \mathrm{consistent} \mathrm{with} \mathrm{autophagy.} \mathrm{All} \mathrm{studies}$ are representative of at least three independent experiments. ${ }^{*} P<0.05$ 
a lipidized form 3 days after TMZ treatment (Figure 3b), suggesting as expected that suppression of beclin 1 levels suppressed TMZ-induced autophagy. shRNA-mediated suppression of beclin 1 did not alter ATP levels in control cells (compare light gray bars in Figure $3 \mathrm{c}$ ) but did significantly suppress the ATP surge noted in shNeg control cells 5 days following TMZ exposure (Figure $3 c$ ). shRNA-mediated suppression of beclin 1 also significantly increased the percentage of cells undergoing micronucleation 5 days after TMZ exposure (Figure $3 d$ ), without altering micronuclation in untreated cells (not shown). Because these data suggested that autophagy was a means by which cells protect themselves from multimicronucleation, and that the autophagy and micronucleation processes might be mutually exclusive, we also stably transfected U251 expressing negative control shRNA or shRNA targeting beclin 1 with constructs encoding GFP-LC3, after cells were incubated with $\mathrm{TMZ}(100 \mu \mathrm{M}, 3 \mathrm{~h})$. Five days later, cells were incubated with DAPI (to stain nuclei) and monitored by fluorescence microscopy for TMZ-induced GFP-LC3 clustering (a marker of autophagy) and multimicronucleation. As shown in Figure $3 e$, untreated cells expressing either the negative control or beclin-targeted shRNA exhibited a diffuse GFP staining consistent with a lack of autophagy (left panels), and no evidence of micronucleation (right panels). TMZ treatment of negative control cells or of cells expressing beclin shRNA led to the appearance of autophagic cells with a punctate GFP appearance and of cells with characteristics of micronucleation (more autophagic cells and fewer micronucleated cells in the negative control group) (Figure $3 e$, arrows). In no instance, however, did cells undergoing micronucleation exhibit punctate GFP staining. These results suggest that autophagy and micronucletion are, to the limits of our detection, mutually exclusive processes in TMZ-treated glioma cells.

Finally, because multimicronucleation may not equate with cell death, we also directly measured the effects of beclin shRNA on the clonagenicity of U251 cells exposed to TMZ. As shown in Figure 4, the same beclin shRNA that suppressed beclin levels, suppressed the TMZ-induced ATP surge, and enhanced TMZ-induced micronucleation also enhanced TMZ-induced cytotoxicty. These data as a whole suggest that TMZ induced autophagy-driven increases in ATP levels protect cells from the drug-induced cell death preceded multimicronucleation.

The TMZ-induced ATP surge is dependent on oxidative phosphorylation. To determine whether the TMZ-induced ATP elevation noted in GBM cells is dependent on catabolic metabolism (mitochondrial ATP production) as would be expected in response to autophagy, we blocked either anabolic metabolism (by inhibition of glycolysis) or catabolic metabolism (by addition of a mitochondrial inhibitor) in TMZtreated cells, and monitored ATP levels and cellular outcome. To do so, U251 cells were treated with TMZ $(100 \mu \mathrm{M}, 3 \mathrm{~h})$ after which the cells were grown in drug-free media for 3 days. The TMZ-exposed cells were grown an additional 2 days in glucose-free media containing 2-deoxyD-glucose (2DG, $10 \mathrm{mM}$ ) (to block glycolysis), or in glucosecontaining media supplemented with a mitochondrial F0, F1-

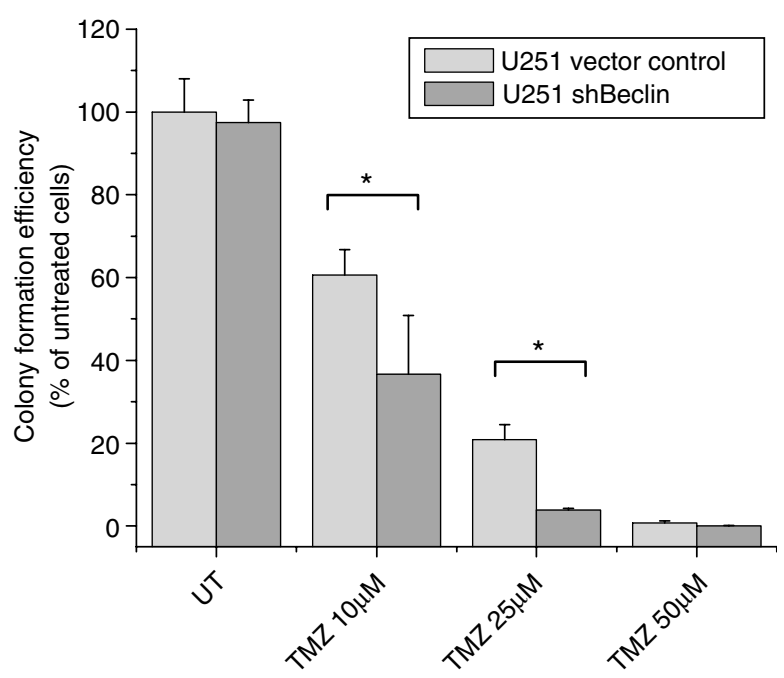

Figure 4 Colony formation efficiency of U251 cells stabley expressing negative control shRNA or shRNA targeting beclin 1 following TMZ exposure $(0-50 \mu \mathrm{M}, 3 \mathrm{~h})$

ATPase inhibitor, oligomycin $(1 \mu \mathrm{M})$ (to block the oxidative phosphorylation). Inhibition of glycolysis with 2DG did not block the TMZ-induced two-fold surge in ATP levels noted 5 or 7 days following TMZ exposure (Figure 5a). 2DG incubation also neither enhanced the percentage of cells undergoing multimicronucleation (not shown) nor altered the extent of micronucleation in TMZ-treated cells (Figure $5 b$ ), suggesting that the ATP surge that contributes to cell protection was not generated by glucose uptake and glycolysis. These results are consistent with the observation that TMZ-treated cells also downregulated GLUT-1, a major glucose transporter, in response to TMZ exposure (Figure 5c). However, when the oxidative phosphorylation in the mitochondria was blocked by exposure of TMZ-treated cells to a nontoxic, nonmicronucleation-inducing exposure of oligomycin $(1 \mu \mathrm{M}$, not shown), the TMZ-induced ATP surge was abolished and the percentage of TMZ-treated cells that died a multimicronucleation-associated death was significantly increased (oligomycin groups, Figures $5 \mathrm{a}$ and b). These results suggest that the TMZ-induced surge in ATP production is dependent not on glycolysis but on oxidative phosphorylation of substrates that can be provided by autophagy.

Because the TMZ-induced ATP surge that was generated by oxidative phosphorylation appeared to protect cells from cell death preceded by multimicronucleation, we tested whether providing exogenous substrates for oxidative phosphorylation to autophagy-deficient cells could enhance ATP levels and suppress cell death preceded by multimicronucleation. For these studies, U251 cells retrovirally infected with constructs encoding non-targeted shRNA or an shRNA targeting beclin 1 were permeabilized with filipin I $(5 \mu \mathrm{M})(\mathrm{a}$ sterol-binding agent that disrupts caveolae to permeabilize the cell $\left.{ }^{17}\right)$, then incubated with pyruvate $(0$ or $25 \mathrm{mM})$ for 2 days beginning 3 days after $\mathrm{TMZ}$ exposure $(0$ or $100 \mu \mathrm{M}, 3 \mathrm{~h})$, after which ATP levels and the percentage of cells undergoing micronucleation were examined. As shown in Figure 5d, ATP 

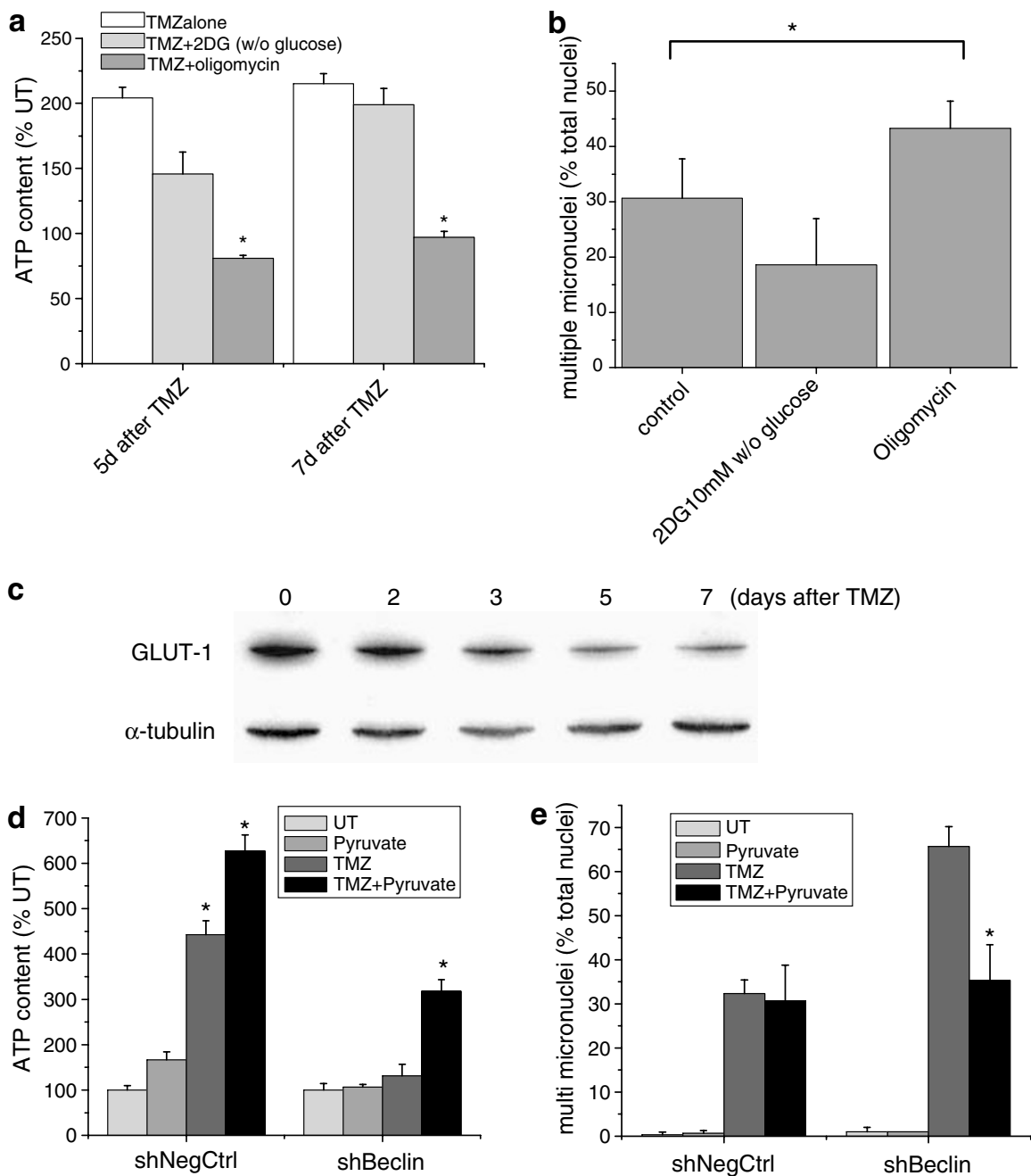

Figure 5 TMZ-induced ATP surge in U251 cells is dependent on oxidative phosphorylation. (a) ATP level per cell (mean \pm S.D., normalized to untreated controls) 5 or 7 days after TMZ treatment $(100 \mu \mathrm{M}, 3 \mathrm{~h})$ with or without exposure to oligomycin $(1 \mu \mathrm{M})$ or glucose-free DMEM supplemented with 2DG $(10 \mathrm{mM})$ in the last 2 days of the study. (b) Percentage of cells exhibiting multimicronucleation 5 days after TMZ treatment ( $100 \mu \mathrm{M}, 3 \mathrm{~h})$ with or without exposure to oligomycin ( $1 \mu \mathrm{M})$ or glucose-free DMEM supplemented with $2 \mathrm{DG}(10 \mathrm{mM})$ in the last 2 days of the study. ${ }^{*} P<0.01$. (c) Immunoblot analyses of GLUT-1 levels in U251 cells $0-7$ days after TMZ treatment $(100 \mu \mathrm{M}$, $3 \mathrm{~h}$ ). (d-e) ATP level per cell (mean \pm S.D., normalized to untreated controls) and the percentage of multimicronucleated cells 5 days after TMZ exposure (0-100 $\mu \mathrm{M}, 3 \mathrm{~h})$ in filipin 1-permeabilized U251 cells stabley expressing negative control shRNA or shRNA targeting beclin 1 and incubated with pyruvate $(0$ or $25 \mathrm{mM})$ in the last 2 days of the study. Data shown are representative of three to five independent experiments. ${ }^{*} P<0.01$

levels were not significantly increased by permeabilization or incubation of shNeg control cells with pyruvate, although consistent with data shown in Figure 3c, TMZ exposure increased ATP levels approximately three- to six-fold in the absence or presence of pyruvate. In contrast, the TMZinduced ATP surge was suppressed in cells expressing shBeclin (compare the third bar in each group in Figure $5 \mathrm{~d}$ ) but could be partially restored by providing pyruvate to the cells. As would be predicted, the genetic suppression of beclin levels also enhanced TMZ-induced multimicronucleation, an effect that could be reversed by provision of pyruvate (Figure 5e). These results suggest that $T M Z$ exposure induces autophagy and enhances ATP production, which in turn helps protect from cell death preceded by multimicronucleation.

To determine if our observations were unique to U251 cells, we repeated studies in two other p53-mutant glioma cells,
U373 and SF188. Like TMZ-treated U251 cells, both TMZtreated U373 and SF188 cells exhibited G2-M arrest at 3-5 days post-TMZ exposure (Figure 6a). The cells also exhibited an LC3-II accumulation at 4-5 days after TMZ treatment, which was inhibited by the delayed addition of 3-MA (Figure 6b). We also observed downregulation of the phosphorylation of S6K and progressive hypophosphorylation of 4E-BP1 in both cell lines, consistent with downregulation of mTOR activity that accompanies autophagy (Figure 6c). As with U251 cells, analyses of ATP levels revealed a significant TMZ-induced elevation of ATP production. The delayed addition of 3-MA, while not altering ATP levels itself (not shown), did inhibit the TMZ-induced surge in ATP production (Figure 6d), suggesting the ATP surge was associated with autophagy. Delayed 3-MA addition, while not altering micronucleation by itself (not shown) also resulted in a significant increase in TMZ-induced multimicronucleation in both cell 
A
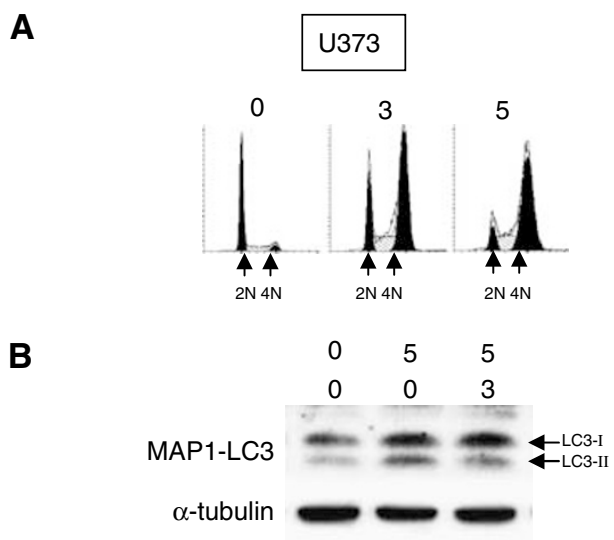
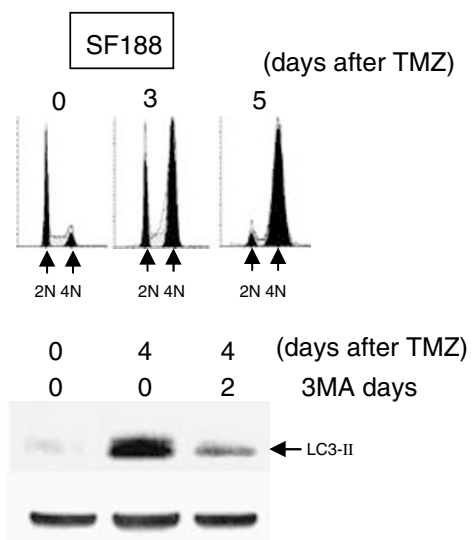

C

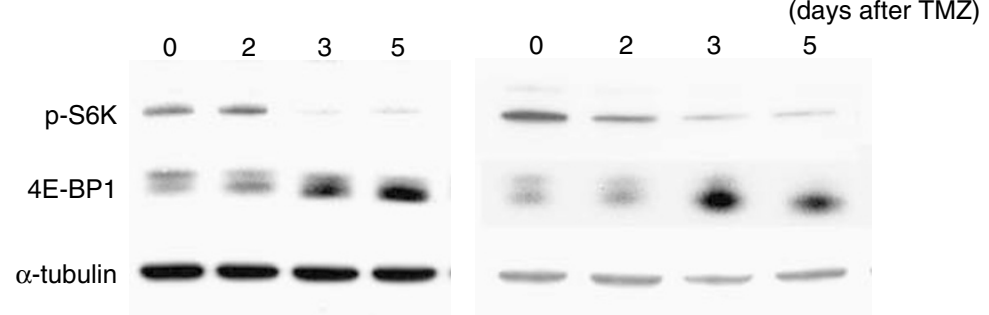

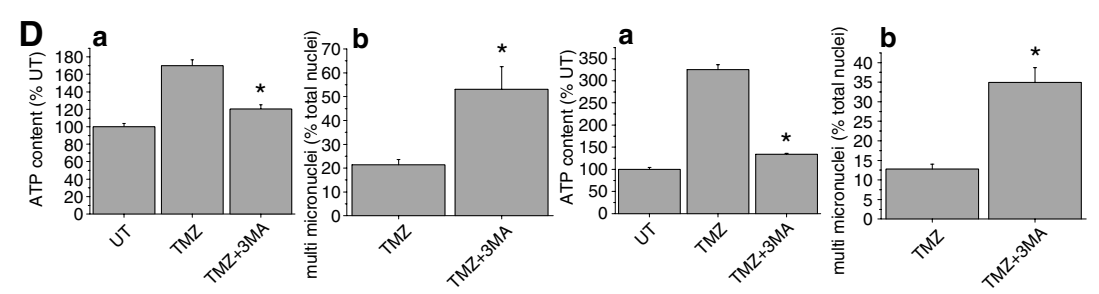

E
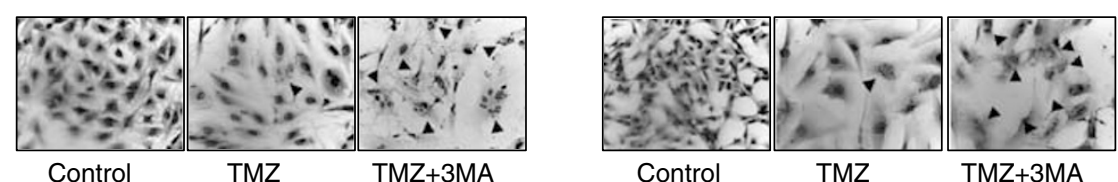

Control

TMZ

$\mathrm{TMZ}+3 \mathrm{MA}$

Figure 6 Effects of TMZ on U373 and SF188 cells. (A) Representative FACS analyses of DNA content of U373 (left panels) and SF188 cells (right panels) 0-5 days after exposure to TMZ (100 $\mu \mathrm{M}, 3 \mathrm{~h}$ ). (B) Immunoblot analysis of the LC3-I and LC3-II forms of MAP1-LC3 in samples obtained from U373 and SF188 control cells (lane 1), cells 4-5 days after TMZ exposure ( $100 \mu \mathrm{M}, 3 \mathrm{~h}$ ) (lane 2), or cells 4-5 days after TMZ exposure (100 $\mu \mathrm{M}, 3 \mathrm{~h}$ ) with the addition of 3-MA (10 mM) in the last 2 days of the study (lane 3). (C) Immunoblot analyses of levels of phospho-S6K, 4E-BP1 in TMZ treated $(100 \mu \mathrm{M}, 3 \mathrm{~h})$ U373 and SF188 cells $0-5$ days following drug exposure. (D) ATP level per cell (mean \pm S.D., normalized to untreated controls) (a), and the percentage of cells exhibiting death associated with multimicronucleation (b) in TMZ treated (100 $\mu \mathrm{M}, 3 \mathrm{~h}) \mathrm{U} 373$ and SF1 88 cells with or without addition of 3-MA ( 0 or $10 \mathrm{mM}$ ) in the last 2 days of the study. (E) Photomicrograph $(400 \times)$ of control, TMZ-treated $(100 \mu \mathrm{M}, 3 \mathrm{~h})$, or TMZ $+3-$ MA ( $0-10 \mathrm{mM}$ in the last 2 days of the study)-treated U373 and SF188 cells 5 (U373 cells) or 4 (SF188 cells) days after TMZ exposure. Arrowheads, multinucleated cells. Data shown are representative of three independent experiments. ${ }^{\star} P<0.01$

lines (Figures $6 d$ and e). These results support the idea that TMZ-induced, autophagy-driven, cytoprotective increases in ATP levels are not unique to U251 cells but are also observed in other glioma cell lines such as U373 and SF188 cells.

Etoposide induces an autophagy-associated ATP elevation. Because it is known that autophagy is induced by multiple DNA damaging agents, ${ }^{3,8}$ we repeated studies in U251 cells using Etoposide to see whether the autophagyassociated cytoprotective ATP surge was unique to TMZ. As shown in Figure $7 \mathrm{a}$, Etoposide $(20 \mu \mathrm{M}, 8 \mathrm{~h})$ induced an Sphase and G2-arrest in U251 cells. Immunoblot analyses revealed the accumulation of LC3-II, which peaked 2 days after Etoposide exposure (Figure 7b). In support of the Etoposide induction of autophagy, we also observed downregulation of the phosphorylation of S6K and progressive hypophosphorylatation of 4E-BP1 indicative of mTOR activity downregulation (Figure 7c). The analyses of levels of ATP revealed an Etoposide-mediated elevation of ATP 3 days after the treatment (Figure 7d) in a time course consistent with the autophagic process, suggesting that this ATP surge was an autophagy-related process. Delayed addition of 3-MA to filipin-permeabilized cells (which did not in itself alter ATP levels or micronucleation - not shown) also suppressed processing of MAP1-LC3 as well as the ATP elevation driven by Etoposide exposure (Figures $7 e$ and $d$, 
a

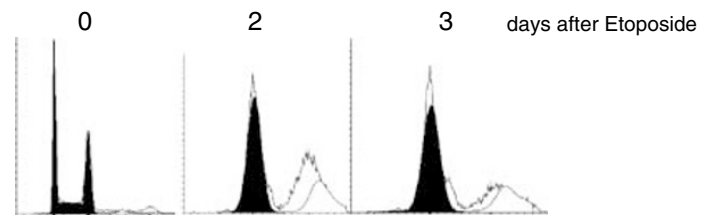

b
C

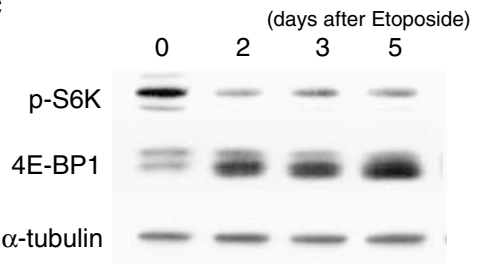

e

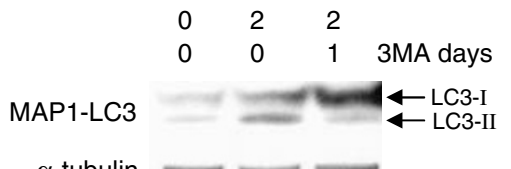

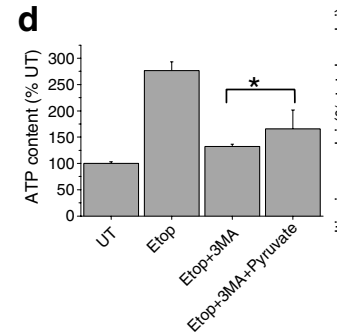
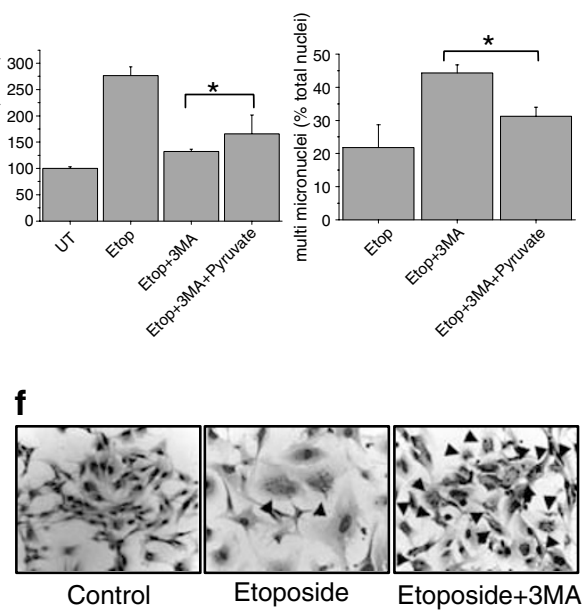

Figure 7 Effect of Etoposide on U251 cells. (a) Representative FACS-based analysis of the DNA content of U251 cells 0-3 days after exposure to Etoposide (20 $\mu \mathrm{M}, 8 \mathrm{~h}$ ). (b) Immunoblot analysis of the LC3-I and LC3-II forms of MAP1-LC3 in U251 cells in 0-5 days after Etoposide exposure (20 $\mu$ M, $8 \mathrm{~h}$ ), or after 1 day rapamycin (RM) exposure $(10 \mathrm{nM})$ as a positive control. (c) Immunoblot analyses of levels of phospho-S6K, 4E-BP1 in Etoposide treated ( $20 \mu \mathrm{M}, 8 \mathrm{~h})$ U251 cells $0-5$ days following drug exposure. (d) ATP levels (mean \pm S.D., normalized to untreated controls) and percentage of multimicronucleated cells 3 days after exposure of filipin-permeabilized U251 cells to Etoposide ( 0 or $20 \mu \mathrm{M}, 8 \mathrm{~h}$ ), 3MA (0 or $10 \mathrm{mM}$ ), and/or pyruvate ( 0 or $25 \mathrm{mM}$ added in the last 2 days of the study). (e) Immunoblot analysis of the LC3-I and LC3-II forms of MAP1-LC3 in control cells (lane 1), cells 2 days after Etoposide exposure $(20 \mu \mathrm{M}, 8 \mathrm{~h})$ (lane 2), or cells 2 days after Etoposide exposure $(20 \mu \mathrm{M}, 8 \mathrm{~h})$ with the addition of 3-MA (10 mM) in the last $24 \mathrm{~h}$ (lane 3). (f) Photomicrograph $(400 \times)$ of hematoxylin/eosin-stained control, Etoposide-treated $(20 \mu \mathrm{M}, 8 \mathrm{~h})$, or Etoposide $+3-\mathrm{MA}(10 \mathrm{mM}$ added in the last $24 \mathrm{~h}$ of the study)-treated cells 2 days after Etoposide exposure. Data shown are representative of three independent experiments. ${ }^{*} P<0.01$

respectively), and significantly increased the percentage of cells eliminated by cell death preceded by multimicronucleation (Figures $7 d$ and $f$ ). Furthermore, as shown in Figure $7 \mathrm{~d}$, co-incubation with pyruvate $(0$ or $25 \mathrm{mM})$ and 3MA (24 $\mathrm{h}$ after starting the Etoposide-treatment), neither of which alone altered ATP levels or micronucleation (not shown) resulted in a statistically significant elevation of levels of ATP $(P<0.01)$, which also partially reversed the enhanced cell death mediated by the addition of 3-MA. Similar results were obtained using SF188 cells (Figures 8a-e). These results suggest that the autophagy-associated ATP surge that protects cells from drug-induced cell death is not unique to $\mathrm{TMZ}$ and can be reproduced by other DNA damaging agents such as Etoposide.

\section{Discussion}

The autophagic process has taken on increased importance following the recognition that it represents a novel form of cell death distinct from apoptosis and necrosis. ${ }^{2,3,18-20}$ The role of drug-induced autophagy, however, is poorly understood, and given the protective role of autophagy in times of cellular starvation, it remains unclear whether the drug-induced autophagy noted following exposure of cells to agents such as $\mathrm{TMZ}$ is protective from, or contributory to, cell death. ${ }^{3,8}$ In this study, we show that autophagy induced by two distinct DNA damaging agents clearly protects several GBM cell lines from cell death preceded by multimicronucleation. Furthermore, this protection is associated with surges in ATP generated not by glycolysis but by oxidative phophorylation. The data presented therefore suggest that part of the cellular response to DNA damaging agents such as $T M Z$ is the autophagic enhancement of catabolic metabolism and ATP levels which in turn provide a degree of cellular protection that may contribute to chemoresistance.

The present work firmly establishes a link between two distinct processes: drug-induced autophagy and suppression of cell death characterized by multimicronucleation. Previous 


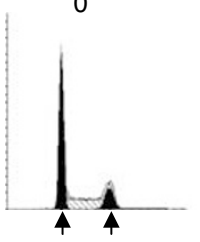

$2 \mathrm{~N} 4 \mathrm{~N}$



(days after Etoposide)

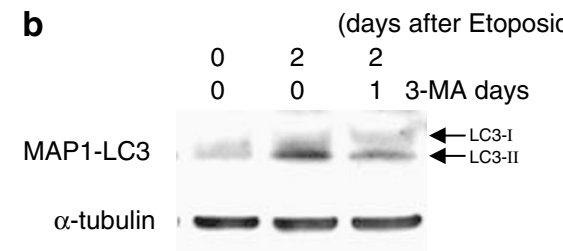

C
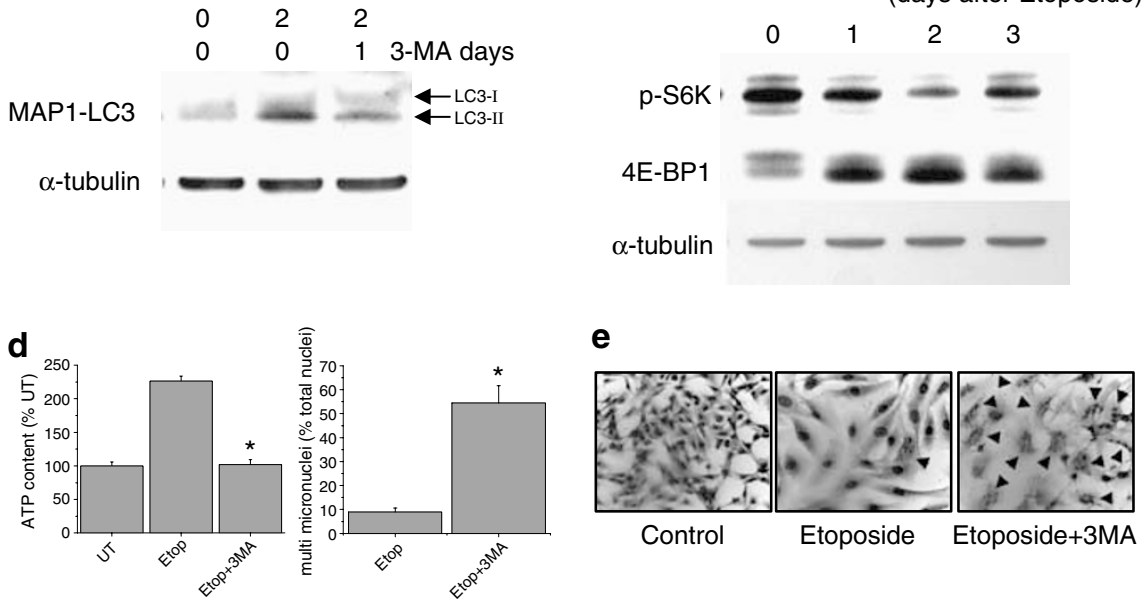

e

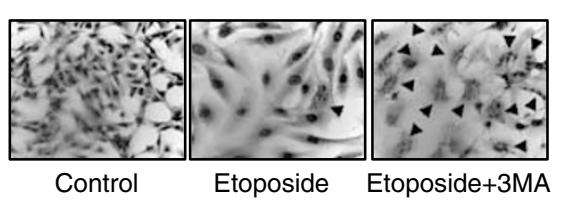

Figure 8 Effect of Etoposide on SF188 cells. (a) Representative FACS-based analysis of DNA contents of SF188 cells $0-2$ days after exposure to Etoposide (20 $\mu \mathrm{M}, 8 \mathrm{~h}$ ). (b) Immunoblot analysis of the LC3-I and LC3-II forms of MAP1-LC3 in SF188 cells in control cells (lane 1), cells 2 days after Etoposide exposure (20 $\mu$ M, $8 \mathrm{~h}$ ) (lane 2 ), or cells 2 days after Etoposide exposure $(20 \mu \mathrm{M}, 8 \mathrm{~h})$ with the addition of 3-MA in the last $24 \mathrm{~h}$ of the study (lane 3$)$. (c) Immunoblot analyses of levels of phospho-S6K, 4E-BP1 in Etoposide treated $(20 \mu \mathrm{M}, 8 \mathrm{~h})$ cells $0-3$ days following drug exposure. (d) ATP level per cell (mean \pm S.D., normalized to untreated controls) and percentage of multimicronucleated cells in cells 2 days after Etoposide treatment, with or without $3 \mathrm{MA}(10 \mathrm{mM})$ in the last $24 \mathrm{~h}$ of the study. (e) Photomicrograph ( $400 \times)$ of $\mathrm{H} / \mathrm{E}$ stained cells of control SF188 cells, cells 2 days after Etoposide exposure $(20 \mu \mathrm{M}, 8 \mathrm{~h})$, or cells 2 days after Etoposide exposure $(20 \mu \mathrm{M}, 8 \mathrm{~h})$ with the addition of 3-MA in the last $24 \mathrm{~h}$ of the study. All data are representative of three independent experiments. ${ }^{*} P<0.01$

work suggested that TMZ exposure induced autophagy in glioma cells and contributed to chemo-resistance, although this study did not examine ATP levels. ${ }^{13}$ In the same study, however, it was also shown that inhibition of TMZ-induced autophagy by 3-MA modestly enhanced cell viability, rather than suppressed it as noted in the present study. In the present study we manipulated the autophagic process 3 days after a brief TMZ exposure (a time frame that coincides with the completion of the cell cycle arrest and the onset of autophagy), rather than continuously during TMZ exposure and cell cycle arrest as in the previous study. This allowed us to analyze the role of autophagy more precisely, and may explain some of the differences noted between the studies.

The present work also definitively shows that the autophagic increase in ATP production was dependent on oxidative phosphorylation following the induction of autophagy, and was also linked to suppression of cell death characterized by multimicronucleation. Previously, it has been reported that autophagy provides growth-factor deprived cells with oxidizable substrates to compensate for the loss of nutrient uptake, and allows cells to maintain ATP production via catabolic metabolism. ${ }^{15}$ The results of the present study are consistent with those derived from growth factor-deprived cells, although the source of substrates for the oxidative phosphorylation in the present study can only be presumed to be autophagolysosome-processed catabolized cellular components. The induction of autophagy following TMZ or Etoposide exposure resulted in a surge of ATP production rather than a sustained elevation as noted following growth-factor deprivation, although the surge in ATP levels was larger than could be induced by supplying exogenous substrates for oxidative phosphorylation. Even relatively small increases in ATP levels, however, led to significant suppression of death characterized by multimicronucleation, suggesting that ATP levels are intimately linked to micronucleation sensitivity. Although the nature of this linkage is not clear, ATP plays a role in cellular maintenance, maintenance of DNA integrity, ${ }^{21}$ and the reinitiation of the cell cycle. ${ }^{22}$ The autophagyassociated surge in ATP may therefore allow cells to maintain normal function in the face of extensive DNA damage. In this sense, autophagy may serve a cooperative role with cell cycle checkpoints in allowing the cell time to deal with DNA damage. Given that TMZ activates signaling pathways that control the G2 checkpoint (including Akt-mTOR ${ }^{23}$ ) as well as the autophagic process, the linkage between DNA damage and the G2 checkpoint may also extend to autophagy. These ideas remain to be examined.

The present work also suggests that drug-induced autophagy and its resultant cytoprotective surge in ATP levels may be a generalized mechanism of resistance to chemotherapeutic agents. The present study shows that two unrelated agents both induce autophagy, a surge in ATP, 
and protection from one form of cell death. Both TMZ and Etoposide, however, are DNA damaging compounds that induced cell cycle arrest, and in this regard autophagy may be a more specific response to compounds that generate potentially lethal DNA damage. Consistent with this idea, the ability of TMZ to induce autophagy is not related to generalized cell stress, but rather to the generation of DNA lesions $\left(\mathrm{O}^{6}\right.$-methylguanine) that lead to DNA damage in the form of DNA single, and double strand breaks (Kanzawa et al. ${ }^{14}$ and unpublished data). The importance of autophagy may also however vary by the genetic background of the cells examined. The present studies were limited to p53-mutant glioma cells because in these cells the predominant form of TMZ-induced cell death is multinucleation rather than apoptosis or senescence. ${ }^{11,12}$ While most GBM are similarly defective in the p53 pathway and presumably influenced by autophagy, tumors of other genetic backgrounds may be less influenced by the autophagic process. These issues remain to be defined.

The present study clearly shows that the autophagic process induced by $\mathrm{TMZ}$ and Etoposide can contribute to resistance to these agents, suggesting that differences in the ability of cells to activate this process may contribute to their sensitivity to these drugs. Modulation of the autophagic pathway may be a novel way of modifying resistance to $T M Z$, Etoposide, and perhaps an even broader range of chemotherapeutic agents, and as such warrants further examination.

\section{Materials and Methods}

Cell culture and reagents. Human malignant glioma U251 and U373 cells were purchased from ATCC (American Tissue Culture Collection, Rockville, MD, USA). Human malignant glioma SF188 cells were obtained from the UCSF Brain Tumor Research Center Tissue Bank (San Francisco, CA). All cells were grown in Dulbecco's modified Eagle's medium plus 10\% fetal bovine serum. TMZ was supplied by the Drug Synthesis \& Chemistry Branch, Developmental Therapeutics Program, Division of Cancer Treatment and Diagnosis, National Cancer Institute and was dissolved in dimethyl sufoxide (DMSO) (Sigma, St Louis, MO). Etoposide, 3-MA, $0^{6}$-benzylguanine (BG), oligomycin, 2-deoxy-D-glucose (2DG), Filipin1 and sodium pyruvate were from Sigma Chemical Co. (St Louis, MO). E-64d and pepstatin were purchased from Calbiochem. Rapamycin was obtained from Cell Signaling Technology.

Drug treatment. For studies examining the effect of TMZ on U251 and U373 cells, unsynchronized, subconfluent cells were exposed to TMZ (0 or $100 \mu \mathrm{M})$ for $3 \mathrm{~h}$, after which the cells were washed, placed in TMZ-free medium, and harvested at appropriate time points. For experiments in SF188 cells, unsynchronized, subconfluent cells were pretreated with $10 \mu \mathrm{M}$ BG for $2 \mathrm{~h}$ to deplete MGMT, followed by incubation with $100 \mu \mathrm{M} \mathrm{TMZ}$ for $3 \mathrm{~h}$ in the presence of $\mathrm{BG}(10 \mu \mathrm{M})$, after which the cells were washed, placed in $\mathrm{BG}(10 \mu \mathrm{M})$ supplemented, TMZ-free media, and grown until harvest. For studies examining the effect of Etoposide in U251 and SF188 cells, the cells were exposed to $20 \mu \mathrm{M}$ Etoposide for $8 \mathrm{~h}$, after which the cells were washed, placed in Etoposide-free medium, and harvested at time points of interest. For all experiments, the cells were plated at least $24 \mathrm{~h}$ before the drug treatment, and final DMSO concentration did not exceed $0.1 \%(\mathrm{v} / \mathrm{v})$.

3-MA was dissolved directly into culture media, aliquoted and stored at $-20^{\circ}$ until used. In the studies using 3-MA, drug-free media was exchanged for media containing 0-10 mM 3-MA beginning 2 days prior to harvest for TMZ-treated cells, and 1 day or 2 days prior to harvest for Etoposide treated cells. 2-DG and oligomycin were dissolved in water and $100 \%$ ethanol respectively, and in studies using these agents, drug-free media was replaced with media containing $1 \mathrm{mM}$ oligomycin or with glucose-free media containing $10 \mathrm{mM}$ 2-DG beginning 2 days prior to harvest. Sodium pyruvate and filipin1 were dissolved in water and $100 \%$ ethanol, respectively, and in studies using these agents, sodium pyruvate and filipin1 were added ( $25 \mu \mathrm{M}$ and $5 \mu \mathrm{g} / \mathrm{ml}$ respectively) to drug-free media beginning 2 days prior to harvest.

Cell cycle studies. Cell cycle analyses were done as previously described. ${ }^{11}$ Briefly, at each time point after the treatment, the cells attached to the culture dish were trypsinized and collected. These cells were washed in PBS, fixed in $70 \%(\mathrm{v} / \mathrm{v})$ ethanol, and stored at $-20^{\circ}$. The cells were washed once with PBS followed by incubation in PBS containing $20 \mu \mathrm{g} / \mathrm{ml}$ propidium iodide (Sigma Chemical Co.) and $100 \mu \mathrm{g} / \mathrm{ml} \mathrm{RNaseA}$ (Sigma Chemical Co.) for $1 \mathrm{~h}$ at room temperature in the dark. Stained nuclei were then analyzed using a Becton Dickinson FACScan (San Jose, CA) with 20000 events/determination. ModFitLT software (Verity Software House, Inc., Topsham, ME) was used to assess cell cycle distribution.

Immunoblot analyses. Preparation of protein samples and Western blot were performed as described previously ${ }^{11}$ with minor modifications. Whole-cell lysate $(0.5-5 \mu \mathrm{g})$ were electrophoresed and electroblotted onto an Immobilon-P membrane (Millipore, Bedford, MA). The membrane was blocked in $5 \%$ skim milk (Bio-Rad Laboratories)/TBST or 5\% BSA (Sigma)/TBST for an hour and probed with antibodies to phosphorylated S6K (Thr389), 4E-BP1 (Cell Signaling Technology, Beverly, MA), GLUT-1 (Chemicon, Temecula, CA), Beclin-1 (BD Pharmingen, Beverly, MA) or $\alpha$-tubulin (Santa Cruz Biotechnology, Santa Cruz, CA) at $4^{\circ} \mathrm{C}$ overnight. Bound antibody was detected with the appropriate horseradish peroxidase-labeled secondary antibodies (Cell Signaling Technology, Beverly, MA and Santa Cruz Biotechnology) using enhanced chemiluminescence Western blotting detection reagents (Pierce, Rockford, IL).

To assess the autophagic processing of MAP1-LC3, the cells were collected separately from the samples above by a modified method as described previously. ${ }^{24}$ Briefly, $3 \mathrm{~h}$ prior to collection of the samples, E64d $(10 \mu \mathrm{g} / \mathrm{ml})$ and pepstatin A $(10 \mu \mathrm{g} / \mathrm{ml})$ were added. After $3 \mathrm{~h}$, the cells were washed with PBS, trypsinized, split into equal halves, and centrifuged to obtain cellular pellets. One half was used to determine protein concentration using Protein Assay reagent (Bio-Rad Laboratories, Hercules, CA) while the other half was lysed directly using LDS sample buffer to achieve a final concentration of $1 \mathrm{ug} / \mathrm{ul}$. Protein aliquots $(10 \mu \mathrm{g})$ were then subjected to the immunoblot analysis and probed with antibodies to MAP1-LC3 $(\mathrm{H}-$ 50) or alpha-tubulin (Santa Cruz Biotechnology, Santa Cruz, CA) at $4^{\circ} \mathrm{C}$ overnight with detection as described above.

Measurement of ATP content. ATP levels were measured as described previously. ${ }^{16}$ Briefly, control and drug-treated cells were trypsinized and collected, counted in triplicate using a Coulter Z2 Particle Count and Size Analyzer (Coulter Corporation, Miami, FL), after which cells (2500-10 000 cells/50 $\mu$ l) were placed in a 96-well plate, eight wells per sample. ATP levels were measured by the luciferinluciferase method using an ATP Bioluminescence Assay Kit (CellTiter-Glo Luminescent Cell viability assay, Promega, USA). A standard curve was generated from known concentrations of ATP for each experiment to reassure the reproducibility of each experiment. Each experiment was carried out at least in triplicate.

Measurement of multimicronucleated cells. For measurement of multimicronucleated cells, cells were seeded on chamber slides (Lab-Tec I chamber slide system, Nalge Nunc, Rochester, NY) at least $24 \mathrm{~h}$ before exposure to TMZ $(100 \mu \mathrm{M}, 3 \mathrm{~h})$ or Etoposide $(20 \mu \mathrm{M}, 8 \mathrm{~h})$. Control cells and cells at each time point after the indicated treatment were fixed with $4 \%$ paraformaldehyde/ $0.25 \%$ Triton $X$ 100/PBS for $10 \mathrm{~min}$ at room temperature, rinsed with PBS, then stained with hematoxylin/eosin. The cells that were large (absent of cytoplasmic shrinkage) and contained separate micronuclei with evenly stained chromatin (absence of chromatin condensation) were defined as multinucleated cells as reported previously. ${ }^{19,25,26}$ The percentage of multimicronucleated cells was determined after scoring more than 100 nuclei for each experiment. Each experiment was repeated at least three times.

shRNA constructs. pSilencer negative control and pSilencer (Ambion, Austin, TX) were a gift from Dr. Yong-Won Kwon (University of California San Francisco). The sequence of the shRNA targeting Beclin-1 was that described in a previous publication, ${ }^{27}$ and the shRNA cassette was subcloned into the BamHI-Hindlll site. U251 cells were transfected by Nucleofector transfection (Amaxa, Gaithersburg, MD) using program T-20. At $48 \mathrm{~h}$ post-transfection, the cells were selected by supplementing DMEM with puromycin $(400 \mathrm{ng} / \mathrm{ml})$ for 7 days to obtain a pooled population of U251 cells stably expressing the shRNA construct. 
Colony formation assay. Colony formation assay was carried out as previously reported. ${ }^{12}$ Briefly, on the day before TMZ treatment, SF126 cells were irradiated (40 Gy) and plated in six-well plates at a density of $5 \times 10^{4}$ cells/well to function as a feeder layer. On the day after, the cells treated with TMZ $(0-50 \mu \mathrm{M}$, $3 \mathrm{~h}$ ) were trypsinized, counted, and plated at a concentration of $100 \mathrm{cells} /$ well into wells of six-well culture plates. 14 days after TMZ exposure, cells were stained with Coumassie blue (BioRad), and colonies of $>50$ cells were counted.

Involvement of LC3. A green fluorescent protein (GFP)-LC3 expression vector was kindly supplied by Dr. S Kondo (University of Texas MD Anderson Cancer Center). U251 expressing a nontargeted shRNA (shNegCtrl) or an shRNA targeting Beclin-1 (shBeclin) were transfected with GFP-LC3 using Fugene (Roche), according to the manufacturer's instruction. At $72 \mathrm{~h}$ after transfection, cells were selected in medium containing $500 \mu \mathrm{g} / \mathrm{ml}$ of G418 (GIBCO) for 7days to obtain stably GFP-LC3 expressing cells. Those cells were treated with TMZ as described above.

Statistical analysis. The data were expressed as means \pm standard deviation (S.D.). Statistical analysis was performed by using Student's $t$-test (two-tailed). The $P$-value is as shown.

1. Yorimitsu T, Klionsky DJ. Autophagy: molecular machinery for self-eating. Cell Death Differ 2005; 12 (Suppl 2): 1542-1552.

2. Lum JJ, DeBerardinis RJ, Thompson CB. Autophagy in metazoans: cell survival in the land of plenty. Nat Rev Mol Cell Biol 2005; 6: 439-448.

3. Levine B, Yuan J. Autophagy in cell death: an innocent convict? J Clin Invest 2005; 115 2679-2688.

4. Petiot A, Pattingre S, Arico S, Meley D, Codogno P. Diversity of signaling controls of macroautophagy in mammalian cells. Cell Struct Funct 2002; 27: 431-441.

5. Ogier-Denis $E$, Codogno P. Autophagy: a barrier or an adaptive response to cancer. Biochim Biophys Acta 2003; 1603: 113-128.

6. Hay N, Sonenberg N. Upstream and downstream of mTOR. Genes Dev 2004; 18: 19261945.

7. Brown EJ, Schreiber SL. A signaling pathway to translational control. Cell 1996; 86: 517-

8. Kondo $\mathrm{Y}$, Kanzawa $\mathrm{T}$, Sawaya $\mathrm{R}$, Kondo $\mathrm{S}$. The role of autophagy in cancer development and response to therapy. Nat Rev Cancer 2005; 5: 726-734.

9. Stupp R, Mason WP, van den Bent MJ, Weller M, Fisher B, Taphoorn MJ et al. Radiotherapy plus concomitant and adjuvant temozolomide for glioblastoma. $N$ Engl J Med 2005; 352: 987-996.
10. Tentori L, Lacal PM, Benincasa E, Franco D, Faraoni I, Bonmassar E et al. Role of wildtype p53 on the antineoplastic activity of temozolomide alone or combined with inhibitors of poly(ADP-ribose) polymerase. J Pharmacol Exp Ther 1998; 285: 884-893.

11. Hirose $Y$, Berger MS, Pieper RO. Abrogation of the Chk1-mediated G(2) checkpoint pathway potentiates temozolomide-induced toxicity in a p53-independent manner in human glioblastoma cells. Cancer Res 2001; 61: 5843-5849.

12. Hirose $Y$, Berger MS, Pieper RO. p53 effects both the duration of $G 2 / M$ arrest and the fate of temozolomide-treated human glioblastoma cells. Cancer Res 2001; 61: 1957-1963.

13. Kanzawa T, Germano IM, Komata T, Ito H, Kondo Y, Kondo S. Role of autophagy in temozolomide-induced cytotoxicity for malignant glioma cells. Cell Death Differ 2004; 11 448-457.

14. Kanzawa T, Bedwell J, Kondo Y, Kondo S, Germano IM. Inhibition of DNA repair for sensitizing resistant glioma cells to temozolomide. J Neurosurg 2003; 99: 1047-1052.

15. Lum JJ, Bauer DE, Kong M, Harris MH, Li C, Lindsten T et al. Growth factor regulation of autophagy and cell survival in the absence of apoptosis. Cell 2005; 120: 237-248.

16. Vander Heiden MG, Chandel NS, Schumacker PT, Thompson CB. Bcl-xL prevents cell death following growth factor withdrawal by facilitating mitochondrial ATP/ADP exchange. Mol Cell 1999; 3: 159-167.

17. Allan EH, Chisholm AB, Titheradge MA. Hormonal stimulation of mitochondrial pyruvate carboxylation in filipin-treated hepatocytes. Biochem J 1983; 212: 417-426.

18. Shintani T, Klionsky DJ. Autophagy in health and disease: a double-edged sword. Science 2004; 306: 990-995.

19. Kroemer G, El-Deiry WS, Golstein P, Peter ME, Vaux D, Vandenabeele $P$ et al Classification of cell death: recommendations of the Nomenclature Committee on Cell Death. Cell Death Differ 2005; 12 (Suppl 2): 1463-1467.

20. Tsujimoto Y, Shimizu S. Another way to die: autophagic programmed cell death. Cell Death Differ 2005; 12 (Suppl 2): 1528-1534.

21. Cotran R, Kumar V, Collins T. Cellular injury and adaptation In Coltran R, Kumar V, Collins T, (eds), Robbins Pathologic Basis of Disease 6th edn W.B. Saunders Company: Philadelphia, PA, USA, 1999; pp. 1-37.

22. van Vugt MA, Bras A, Medema RH. Restarting the cell cycle when the checkpoint comes to a halt. Cancer Res 2005; 65: 7037-7040.

23. Hirose Y, Katayama M, Mirzoeva OK, Berger MS, Pieper RO. Akt activation suppresses Chk2-mediated, methylating agent-induced G2 arrest and protects from temozolomideinduced mitotic catastrophe and cellular senescence. Cancer Res 2005; 65: 4861-4869.

24. Tanida I, Minematsu-lkeguchi $\mathrm{N}$, Ueno $\mathrm{T}$, Kominami $\mathrm{E}$ Lysosomal turnover, but not cellular level, of endogenous LC3 is a marker for autophagy. Autophagy 2005; 1: 84-91.

25. Castedo M, Perfettini JL, Roumier T, Andreau K, Medema R, Kroemer G. Cell death by mitotic catastrophe: a molecular definition. Oncogene 2004; 23: 2825-2837.

26. Roninson IB, Broude EV, Chang BD. If not apoptosis, then what? Treatment-induced senescence and mitotic catastrophe in tumor cells. Drug Resist 2001; 4 (Update): 303 313

27. Yu L, Alva A, Su H, Dutt $P$, Freundt E, Welsh $S$ et al. Regulation of an ATG7-beclin 1 program of autophagic cell death by caspase-8. Science 2004; 304: 1500-1502. 